\title{
Factors associated with refusal to enter a clinical trial: epidural anesthesia is a deterrent to participation
}

\author{
[Les facteurs associés au refus de participer à un essai clinique : l'anesthésie \\ péridurale est un élément dissuasif]
}

Timothy V. Salomons BA BSc, ${ }^{*}$ Adarose Ardiel Wowk BSc Rn, ${ }^{*}$ Ann Fanning FFArCSI, $\dagger$ Vincent W.S. Chan MDCM FRCPC, $\ddagger$ Joel Katz PhD\$

Purpose: To compare patients who participate in a clinical trial for pain management involving epidural anesthesia to those who refuse and document their reasons for refusing.

Methods: Demographic and health history information was collected from 621 female patients who were screened for inclusion in a pain management trial involving epidural anesthesia. Patients who completed the clinical trial $(n=149)$ were compared to those who consented to provide screening information but did not enter the trial $(n=472)$.

Results: Sixty-seven percent of women who refused cited unwillingness to have an epidural as the reason for their decision. NonCaucasians $(P<0.01)$, patients with no history of mood/anxiety disorders $(P<0.016)$ or systemic disease $(P<0.02)$, and patients with certain types of pain $(P<0.02)$ were more likely to refuse to participate in the clinical trial. A longer duration between recruitment and surgery was also found to be associated with higher participation rates $(P<0.01)$. A logistic regression equation significantly predicted which patients would participate or refuse $(P<0.000$ I), indicating that a specific set of health and demographic factors strongly influence the decision to participate in a trial.

Conclusions: The decision to participate in a clinical trial is viewed as a risk/benefit analysis. Factors such as short recruitment to surgery intervals and pre-existing pain, which increase the salience of risks associated with the trial, may result in lower participation rates. Overall, epidural anesthesia is a strong deterrent to participation in a clinical trial.
Objectif : Comparer les patients qui refusent de participer à des essais cliniques sur l'analgésie comportant l'anesthésie péridurale et documenter les raisons de leur refus.

Méthode : Les données démographiques et médicales ont été recueillies auprès de 621 femmes choisies pour participer à un essai sur le traitement de la douleur comportant l'anesthésie péridurale. Les patientes qui ont participé à l'essai clinique $(n=149)$ ont été comparées à celles qui ont accepté de fournir les informations nécessaires à la sélection mais qui n'ont pas fait partie de l'étude $(n=472)$.

Résultats : Des femmes qui n'ont pas voulu participer à l'essai, $67 \%$ ont justifié leur décision par le refus d'une anesthésie péridurale. Les patientes de race non blanche $(P<0,01)$, sans antécédents de trouble de l'humeur ou d'anxiété $(P<0,016)$ ou de maladie systémique $(P<0,02)$, et celles qui présentaient certains types de douleur $(P<0,02)$ avaient davantage tendance à refuser de participer. Un plus long intervalle entre le recrutement et l'intervention chirurgicale était aussi associé à un taux plus élevé de participation $(P<0,01)$. Une équation de régression logistique a permis de prédire de façon significative quelles patientes allaient participer ou non ( $P<0,000 \mathrm{I}$ ), indiquant qu'un ensemble spécifique de facteurs médicaux et démographiques influencent fortement la décision.

Conclusion : La décision de participer à un essai clinique a été considérée comme une analyse risques-avantages. Des facteurs comme un court intervalle entre le recrutement et l'opération et des douleurs préexistantes augmentent les possibilités de risques associés à l'essai et peuvent entraîner de faibles taux de participation. Dans l'ensemble, l'anesthésie péridurale est un élément dissuasif important de participation à un essai clinique.

From the Acute Pain Research Unit, Department of Anaesthesia and Pain Management, ${ }^{*}$ University Health Network and Mount Sinai Hospital, Toronto, Ontario, Canada; the Department of Anesthesia, $†$ Our Lady's Hospital, Navan Ireland; the Regional Anesthesia and Acute Pain Service, $\ddagger$ University Health Network, University of Toronto, Toronto, Ontario, Canada; and the Acute Pain Research Unit, Department of Anaesthesia and Pain Management, $\$$ University Health Network and Mount Sinai Hospital, University of Toronto,

Toronto, Ontario, Canada.

Address correspondence to: Dr. Joel Katz, Department of Anaesthesia and Pain Management, University Health Network, EN 3-440,

200 Elizabeth Street, Toronto, Ontario M5G 2C4, Canada. Phone: 416-340-3777; Fax: 416-340-3698; E-mail: jkatz@uhnres.utoronto.ca Received from the Acute Pain Research Unit, Department of Anaesthesia and Pain Management, Toronto General Hospital, University

Health Network, Toronto, Ontario, Canada. Supported in part by Grant \#MOP-37845 from the Canadian Institutes of Health Research

(CIHR), Ontario, Canada, a CIHR Investigator Award to Dr. Katz, and Grant \#NS35480 from the National Institutes of Health, Bethesda, Maryland. Presented in part at the $20^{\text {th }}$ Annual Scientific Meeting of the American Pain Society,

Phoenix, Arizona, USA (April 20, 2001). Accepted for publication January 14, 2002.

Revision accepted March 13, 2002. 
$\mathrm{T}$

HE medical community relies on clinical trials to test the safety and efficacy of new treatments. The validity of findings depends on the extent to which the sample represents the population of interest. Ethical concerns dictate that participation in clinical trials be voluntary. Voluntary participation, however, may compromise the generalizability of results, ${ }^{1}$ since it is unclear how patients who refuse differ from those who agree to participate.

The aim of this study is to compare patients who agreed to participate in a clinical trial involving epidural anesthesia with those who declined.

\section{Methods}

This study was approved by the University Health Network and Mount Sinai Hospital Research Ethics Boards. Data were collected between 1995 and 2000.

\section{Population}

The target population was women between 19 and 75 yr of age undergoing major gynecological procedures by laparotomy. Patients with ASA scores $>2$ or contraindications to any of the trial procedures were excluded.

\section{Recruitment}

Patients at two large urban teaching hospitals were approached by a research nurse at their pre-admission appointment. During screening, patients were asked to provide verbal consent to answer demographic and health history questions and have their chart reviewed. Eligible patients were given a standardized description of the clinical trial and asked to sign informed consent.

Patients were asked to enter a pain management trial involving epidural anesthesia. Epidural anesthesia is not standard practice for abdominal-gynecological surgery at either hospital; only patients who participated in the trial would receive an epidural.

\section{Sample}

The present study consists of two groups of women: the refuser group $(n=472)$ who consented to provide demographic and health history information and have their chart reviewed but declined to participate in the clinical trial; and the participant group $(n=149)$ who signed consent and completed the study or were withdrawn for protocol violations occurring intra-operatively or postoperatively. Patients who initially consented but dropped out before surgery $(n=60)$ were not included.
TABLE I Variables that differentiate patients who refuse because of the epidural from those who refuse for other reasons. Data are mean \pm SD unless otherwise stated.

\begin{tabular}{|c|c|c|c|}
\hline \multirow[b]{2}{*}{ Variable } & \multicolumn{3}{|c|}{ Reason given for refusing to participate } \\
\hline & Epidural & Other & P value \\
\hline $\begin{array}{l}\text { Age }(\text { mean } y r \pm S D) \\
\text { (total } n=466)\end{array}$ & $45 \pm 9.6$ & $48 \pm 11.0$ & 0.005 \\
\hline $\begin{array}{l}\text { Pain history }[n(\%)] \\
\text { (total } n=462)\end{array}$ & & & 0.013 \\
\hline Yes & $56(40)$ & $171(53)$ & \\
\hline No & $83(60)$ & $152(47)$ & \\
\hline $\begin{array}{l}\text { Smoker }[n(\%)] \\
(\text { total } n=366)\end{array}$ & & & 0.002 \\
\hline Yes & $10(9)$ & $57(23)$ & \\
\hline No & $103(91)$ & $196(77)$ & \\
\hline
\end{tabular}

\section{Statistical analysis}

Continuous variables were analyzed by multivariate ANOVA. Categorical variables were analyzed using chi- squared tests. $P<0.05$ was considered statistically significant. Eighteen cases with outliers more than three standard deviations from the mean were removed from analysis.

Binary logistic regression was performed to predict whether patients would be likely to refuse or participate. Since cases with missing data could not be evaluated using the logistic regression, missing values were replaced for the logistic regression analysis, but only for variables with less than $10 \%$ of data missing.

The database was split in half randomly, using the SPSS "select cases" function choosing the "random sample of cases" option from the entire database with one half used to generate the regression equation and the other used to test it. The final model was chosen for low log likelihood (a measure of the probability of obtaining the observed results given the parameter estimates), parsimony and the ability to predict refusers and participants equally.

Data were analyzed using SPSS for Windows 9.0, Chicago, IL, USA.

Additional information regarding the clinical trial, a full list of variables analyzed, methods of replacing missing data and the logistic regression analysis are available at www.cja-jca.org.

\section{Results}

\section{Reasons for refusal}

Four hundred and fifty-one patients gave a reason for declining to participate in the clinical trial. Thirty-five of these patients gave an additional reason. The most com- 
TABLE II Variables associated with patient participation. Data are mean \pm SD unless otherwise stated.

\begin{tabular}{|c|c|c|c|}
\hline Variable & Refusers & $\begin{array}{l}\text { Group } \\
\text { Participants }\end{array}$ & P value \\
\hline \multicolumn{3}{|c|}{ Type of pain [n (\%)] } & \multirow[t]{6}{*}{0.023} \\
\hline No pain & $234(52)$ & $79(55)$ & \\
\hline Abdominal & $133(29)$ & $33(23)$ & \\
\hline Back & $38(8)$ & $10(7)$ & \\
\hline Headache & $16(4)$ & $8(6)$ & \\
\hline Other & $33(7)$ & $13(9)$ & \\
\hline \multicolumn{3}{|c|}{ ASA status [n (\%)] } & \multirow[t]{3}{*}{0.023} \\
\hline ASA I & $319(69)$ & $86(59)$ & \\
\hline ASA > I & $140(31)$ & $59(41)$ & \\
\hline \multicolumn{3}{|l|}{$\operatorname{Race}[n(\%)]^{*}$} & \multirow[t]{3}{*}{0.010} \\
\hline Caucasian & $180(61)$ & $77(75)$ & \\
\hline Other & $117(39)$ & $26(25)$ & \\
\hline \multicolumn{3}{|c|}{ Psychiatric history $[n(\%)]^{* *}$} & \multirow[t]{3}{*}{0.016} \\
\hline Yes & $43(9)$ & $24(16)$ & \\
\hline No & $427(91)$ & $124(84)$ & \\
\hline Nurse $(n=585)$ & $\mathrm{n} / \mathrm{a}^{* * *}$ & $\mathrm{n} / \mathrm{a}^{* * *}$ & 0.001 \\
\hline \multicolumn{3}{|c|}{ Hospital site $(n=617)$} & \multirow[t]{3}{*}{0.001} \\
\hline Site 1 & $207(44)$ & $39(26)$ & \\
\hline Site 2 & $262(56)$ & $109(74)$ & \\
\hline \multicolumn{4}{|c|}{ Days before surgery } \\
\hline$(n=566)$ & $7.4 \pm 4.6$ & $8.5 \pm 5.0$ & 0.010 \\
\hline $\begin{array}{l}\text { Weight }(\mathrm{kg}) \\
(n=566)\end{array}$ & $67 \pm 12.1$ & $70 \pm 13.0$ & 0.022 \\
\hline \multicolumn{3}{|l|}{ Height $(\mathrm{cm})$} & 0.010 \\
\hline
\end{tabular}

* Due to relatively low numbers of non-Caucasians who participated in the clinical trial, patients were grouped into "Caucasian" and "non-Caucasian" for analysis. * * Since patients with a history of major psychiatric disorder were excluded from the clinical trial, most patients who were classified as having a psychiatric history were those who reported having diagnosed mood or anxiety disorders in the past or current symptoms which were well controlled. $* * *$ The categories in "nurse" represent individual differences between 11 different research nurses and were not considered of interest to a general audience. Success rates of individual nurses (patients recruited: patients approached) ranged from $0-48 \%$.

mon response was unwillingness to have an epidural ( $n$ $=329,67 \%)$. Seventy-seven patients $(16 \%)$ refused for emotional reasons. Forty-nine patients (10\%) did not want additional medical interventions. Twenty-two patients $(5 \%)$ stated they were not interested in the clinical trial. Nine patients gave uncategorizable responses.

To investigate the hesitation of many patients to receive an epidural, results were collapsed into two groups: those who refused to participate because of the epidural and those who refused for other reasons (Table I).

\section{Comparison of participants and refusers}

Table II shows the results of the comparison between participants and refusers.

The logistic regression equation was generated and
TABLE III Predicted and observed (actual) group membership (refuser or participant) for the independent subsample used to the generate logistic regression equation and the independent subsample used to test the equation $(P<0.0001)$.

\begin{tabular}{lccc}
\hline & $\begin{array}{l}\text { Predicted } \\
\text { refusers }(n)\end{array}$ & $\begin{array}{l}\text { Predicted } \\
\text { participants }(n)\end{array}$ & \% Correct \\
\hline Independent subsample used to generate & the logistic regression equation \\
Actual refusers $(n)$ & 149 & 76 & 66.2 \\
Actual participants $(n)$ & 25 & 50 & 66.7 \\
Overall \% correct & 66.3 & & \\
& & & \\
Independent subsample & used to test the logistic regression equation \\
Actual refusers $(n)$ & 141 & 84 & 62.7 \\
Actual participants $(n)$ & 28 & 46 & 62.2 \\
Overall \% correct & 62.5 & & \\
\hline
\end{tabular}

tested by randomly selecting two independent subsamples with no common cases $(n=225$ refusers and $n=75$ participants to generate the equation and $n=$ 225 refusers and $n=74$ participants to test it; Table III). The area under the receiver-operator characteristics curve for the model was 0.7 , indicating the model performed significantly better than chance $(P<$ $0.0005)$. Table IV shows the variables included in the logistic regression equation.

\section{Discussion}

While this study focused on health and demographic information, it is the specific demands of the clinical trial that primarily determine participation rates. ${ }^{2}$ Patients who refuse to enter a clinical trial are most likely to cite the aversive aspects of the trial as the reason for their decision, while those who participate are most likely to cite perceived benefits. ${ }^{3}$ This suggests that the decision to enter a clinical trial involves a risk-benefit analysis. In addition to examining the reasons given for refusal, the present study investigated whether health and demographic factors are associated with the decision to participate or not.

Several factors were associated with lower participation rates in this sample. The fewer days before surgery patients were approached, the more likely they were to refuse. As the patient's surgery approached, it is possible that the potential risks weighed more heavily in the decision making process.

In addition, patients with certain types of pain were more likely to refuse. Patients with abdominal and back pain had higher rates of refusal than patients without pain. This was not observed for patients with headache or other types of pain. Patients with back pain may have been more hesitant to have an epidural, while patients with abdominal pain may have been more apprehensive 
TABLE IV Variables included in the logistic regression model

\begin{tabular}{|c|c|c|}
\hline Variable & Beta coefficient* & Relationship \\
\hline Number of surgeries & 0.071 & $\begin{array}{l}\text { The more previous surgeries a patient has had } \\
\text { the more likely they are to participate. }\end{array}$ \\
\hline Psychiatric history & -0.811 & $\begin{array}{l}\text { Patients with a negative history are less } \\
\text { likely to participate. }\end{array}$ \\
\hline Age & -0.016 & Younger patients are more likely to participate. \\
\hline ASA status & 0.063 & $\begin{array}{l}\text { Patients with systemic disease are more likely } \\
\text { to participate than healthy patients. }\end{array}$ \\
\hline \multicolumn{3}{|l|}{ Pain history } \\
\hline Abdominal pain & -0.266 & Patients with abdominal or back pain are less \\
\hline Back pain & -0.766 & likely to participate than patients with no pain \\
\hline Headache & 0.814 & history. Patients with other types of pain are \\
\hline Other & 0.195 & more likely to participate. \\
\hline Days before surgery & 0.077 & $\begin{array}{l}\text { The greater the number of days before surgery } \\
\text { the patients are approached, the more likely } \\
\text { they are to participate. }\end{array}$ \\
\hline Previous epidural & -0.846 & $\begin{array}{l}\text { Patients who have not had a previous epidural are } \\
\text { likely to participate. }\end{array}$ \\
\hline Height & 0.004 & Taller patients are more likely to participate. \\
\hline \multicolumn{3}{|l|}{ Nurse \% recruited } \\
\hline $0-15 \%$ & -1.136 & Individual differences between nurses \\
\hline $16-30 \%$ & 0.275 & $\begin{array}{l}\text { are important in determining whether or not } \\
\text { a patient participates. }\end{array}$ \\
\hline Hospital site & -0.8176 & $\begin{array}{l}\text { Patients from one hospital site are less } \\
\text { likely to participate than patients from the other site. }\end{array}$ \\
\hline $\begin{array}{l}\text { Constant of logistic } \\
\text { regression equation }\end{array}$ & 1.1538 & \\
\hline
\end{tabular}

* More information on beta coefficients is presented along with the online version of this article.

about their impending abdominal surgery and unwilling to undergo additional interventions.

The data also suggest that prior experience in a medical setting may increase the likelihood that a patient will consent. Patients with a history of systemic disease, diagnosed mood or anxiety disorders or greater number of previous surgeries were more likely to participate. These patients likely had more contact with the medical system than asymptomatic patients. This may have reduced the perceived risk and uncertainty associated with participating. While these results do not conclusively support this interpretation, they suggest an area for future research.

The salience of reduced postoperative pain as a potential benefit of research also merits further study. The clinical trial studied here involved no treatment for the patient's primary diagnosis. The potential for improved treatment increases the likelihood that a patient will participate in research. ${ }^{4}$ Determining the importance to the patient of improved pain management may help predict whether a patient will participate in a clinical trial of this type.

The results confirm previous findings ${ }^{5}$ that epidural anesthesia is a deterrent to participation in a clinical trial. Resistance to epidural anesthesia as presented in the context of a clinical trial appears to be related to age, with younger persons more likely to refuse because of unwillingness to have an epidural. The nature and origins of these attitudes require study.

The unpopularity of epidural anesthesia also raises questions about the generalizability of these results. Would patients who refused due to the epidural have participated in other research that did not involve epidural anesthesia? Would they have consented to an epidural had it been in the context of routine clinical practice? Further research is needed to determine the extent to which the results obtained here can be generalized to clinical trials with different risk/benefit profiles.

Finally, there is an inherent difficulty in obtaining an accurate portrait of patients who refuse to participate in clinical trials. Our refuser group consisted of patients who agreed to be screened. However, there is no ethical way of obtaining data from the "true refusers" who will not provide any information for research purposes.

\section{References}

1 Jones $J$. The effects of non-response on statistical inference. J Health Soc Policy 1996; 8: 49-62.

2 Ross S, Grant A, Counsell C, Gillespie W, Russell I, Prescott R. Barriers to participation in randomised controlled trials: a systematic review. J Clin Epidemiol 1999; 52: 1143-56. 
3 Barofsky I, Sugarbaker PH. Determinants of patient nonparticipation in randomized clinical trials for the treatment of sarcomas. Cancer Clin Trials 1979; 2: 237-46.

4 Charlson ME, Horwitz RI. Applying results of randomised trials to clinical practice: impact of losses before randomisation. Br Med J Clin Res Ed 1984; 289: 1281-4.

5 van den Berg L, Lobatto RM, Zuurmond WWA, de Lange JJ, Wagemans MFM, Bezemer PD. Patients' refusal to participate in clinical research. Eur J Anaesthesiol 1997; 14: 287-9.

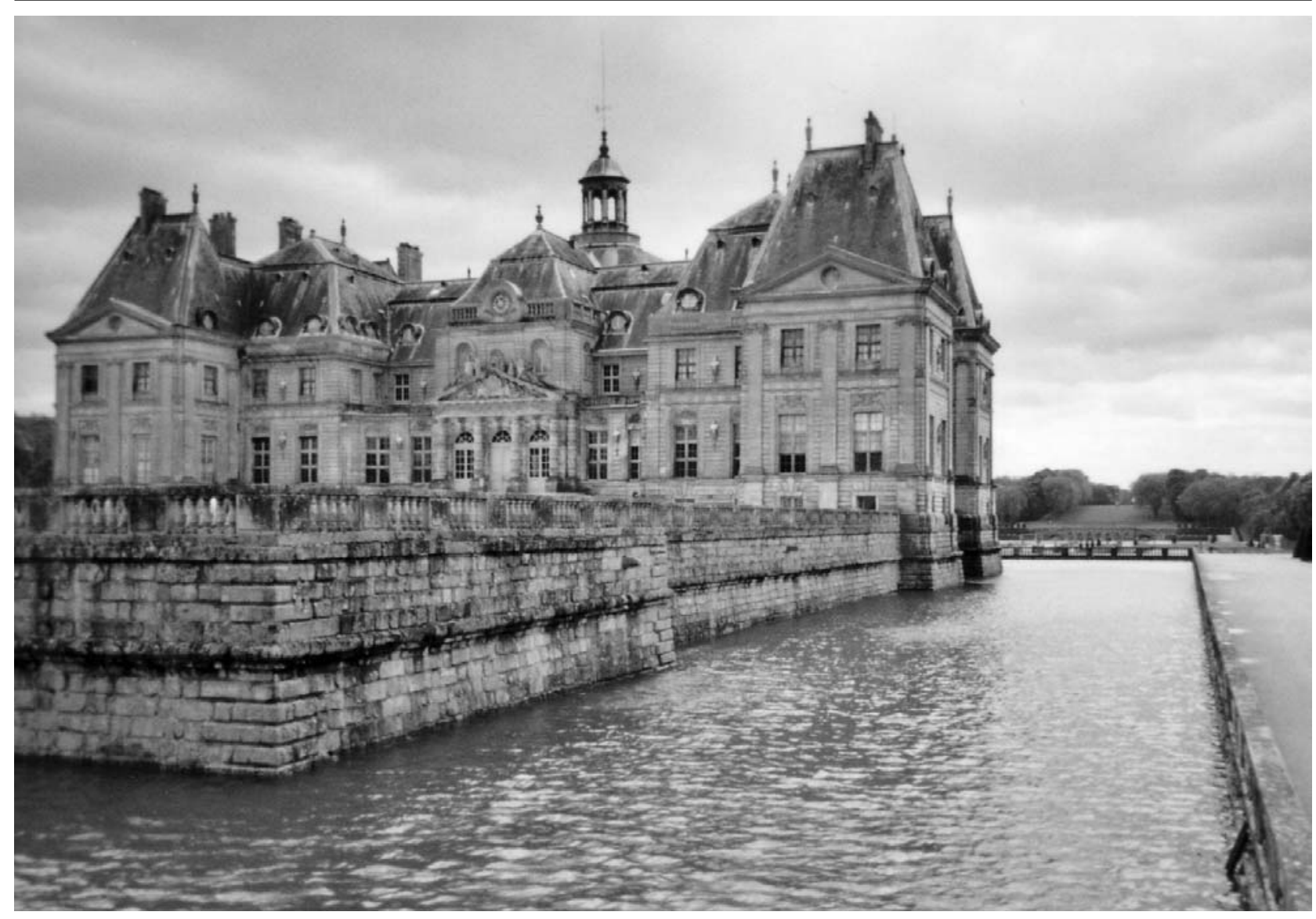

Château de Nicolas Fouquet, Vaux-le-Vicomte - France 